\title{
CONTENTS
}

GOTTFRIED T. RÜTTIMANN. Stable faces of a polytope

P. H. MASERICK. Moments of measures on convex bodies

B. J. MATKOWSKY and Z. SCHUSS. On the problem of exit

JOHN V. RYFF. The functional equation $a f(a x)+b f(b x+a)=b f(b x)+a f(a x+b)$ extensions and almost periodic solutions

DAVID A. EDWARDS and HAROLD M. HASTINGS. Generalized Steenrod homology theories

DENNIS SULLIVAN. A new flow

WILLIAM ABIKOFF. Augmented Teichmüller spaces

DAVE RIFFELMACHER. Three partial orders arising from multiplication alteration by two-cocycles

ALEXANDRA BELLOW. Stability properties of the class of asymptotic martingales .... 338

W. M. GREENLEE. Singular perturbation theory for semibounded operators ............... 341

CZES KOSNIOWSKI. Generators of the unitary $\mathrm{Z} / p$ bordism ring ............................ 344

ARYEH DVORETZKY. On stopping time directed convergence ............................. 347

R. D. GENTRY and C. C. TRAVIS. Existence and comparison of eigenvalues of $n$th order linear differential equations

\section{COUNCIL, 1976}

\section{PUBLICATIONS COMMITTEES *}

Robert G. Bartle (26, 28, 46, 47), Hyman Bass (18), Alexandra Bellow (46, 47), James H. Bramble $(65,35)$, Edgar H. Brown, Jr. (55, 57), Alberto P. Calderón $(26,42,44,35)$, Thomas A. Chapman (57 A, 57C), S. S. Chern (53), Philip T. Church (54, 55, 57, 58), Chandler Davis $(15,41,47,65 F)$, Samuel Eilenberg $(18,68)$, Solomon Feferman $(02 A-K, 04,18 A)$, Robert M. Fossum $(12,13,14,16,18)$, Walter Gautschi (65D, F, L, Q), Richard R. Goldberg (40, 42, 43, 44, 46J), Paul R. Halmos (02, 04, 15, 28, 46, 47), Alston S. Householder (15A03-24, 65 F, 65H05), D. J. Lewis (10), Richard K. Miller $(33,35,46,77)$, Barbara L. Osofsky $(16,18,13)$, Maxwell A. Rosenlicht (12, $12 \mathrm{H05}, 14,15,20 \mathrm{G})$, Jacob T. Schwartz (68, 93, 94), Robert T. Seeley $(35,33,46,47)$, Stephen S. Shatz $(14,13,12)$, I. M. Singer $(46,53,58)$, Daniel W. Stroock $(60,62)$, Olga Taussky Todd $(12,15)$, Hans F. Weinberger $(35,45,49)$, Joseph A. Wolf $(22,53)$, John W. Wrench, Jr. (10.25, 33, 65.05, 65.25).

\section{OTHER MEMBERS OF THE COUNCIL}

Paul T. Bateman, Lipman Bers, R. H. Bing, Charles W. Curtis, David Gale, Walter H. Gottschalk, Mary W. Gray, Judy Green, Phillip A. Griffiths, Orville G. Harrold, Jr., Herbert B. Keller, Robion C. Kirby, Lee Lorch, John W. Milnor, Louis Nirenberg, Karl K. Norton, Franklin P. Peterson, Everett Pitcher, Murray H. Protter, Kenneth A. Ross, Hugo Rossi, Lee A. Rubel, Jane Cronin Scanlon, Barry Simon, Daniel Waterman, Guido L. Weiss, J. Ernest Wilkins, Jr.

\footnotetext{
* Research announcements, limited to 100 typed lines of 65 spaces each, may be submitted to those members of the Council who are members of the publications committees. Such announcements are intended to communicate outstanding results that are to be reported in full elsewhere.
} 


\title{
CONTENTS
}

\author{
March, 1976
}

ADRIANO M. GARSIA. Combinatorial inequalities and smoothness of functions ......

NOLAN R. WALLACH. On the Selberg trace formula in the case of compact quotient

\section{BOOK REVIEWS}

R. STONG. Algebraic topology-homotopy and homology by Robert M. Switzer ....... GEORGE R. SELL. Almost periodic differential equations by A. M. Fink; Nonlinear differential equations of higher order by R. Reissig, G. Sansone and R. Conti; and Functional differential equations by J. K. Hale

A. F. MONNA. Fourier analysis on local fields by M. H. Taibleson

WILHELM STOLL. Introduction to the theory of entire functions of several variables by L. I. Ronkin

MARVIN I. KNOPP. Elliptic modular functions by B. Schoeneberg ........................

D. W. STROOCK. The theory of stochastic processes. I by I. I. Gihman and A. V. Skorohod; Stochastic calculus and stochastic models by E. J. McShane; Mesures cylindriques, espaces de Wiener, et fonctions aléatoires Gaussiennes by Albert Badrikian and Simone Chevet; Almost sure convergence by William F. Stout; and Integration in Hilbert space by A. V. Skorohod

STEPHEN S. SHATZ. Geometric theory of algebraic space curves by S. S. Abhyankar and A. M. Sathaye

IAN N. SNEDDON. The functions of mathematical physics by Harry Hochstadt ..... ARNE MAGNUS. Essentials of Padé approximants by George A. Baker, Jr.

MARY KATHERINE BENNETT. Distributive lattices by Raymond Balbes and Philip Dwinger

R. T. SEELEY. Pseudo-differential operators by Michael Taylor

Elections to Membership

\section{RESEARCH ANNOUNCEMENTS}

JOHN W. GARRETT and ČASLAV V. STANOJEVIĆ. Integrability of shifted trigonometric series

JOAN S. BIRMAN and R. CRAGGS. On the $\mu$-invariant of Z-homology 3-spheres ...

JOHN CANTWELL and LAWRENCE CONLON. Open leaves in closed 3-manifolds..

JOHN B. CONWAY and ROBERT F. OLIN. A functional calculus for subnormal operators

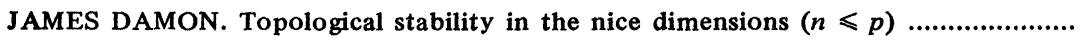

DAVID A. DRAKE and HANFRIED LENZ. Finite Hjelmslev planes with new integer invariants

PAUL GERARDIN. Three Weil representations associate to finite fields

A. W. KNAPP. Commutativity of intertwining operators. II

NIMROD MEGIDDO. Partial and complete cyclic orders

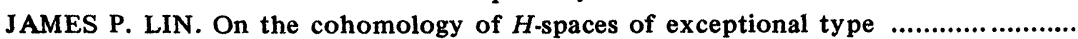

ROBERT OLIVER. Fixed points of disk actions

CLINT MCCRORY. Cobordism operators and singularities of maps .........................

O. S. ROTHAUS. On the nontriviality of some group extensions given by generators and relations

SHAIR AHMAD and A. C. LAZER. Component properties of second order linear systems

WILLIAM M. SINGER. Iterated loop functors and the homology of the Steenrod algebra

R. T. SMITH. Examples of elliptic complexes

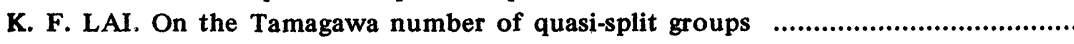

ALFRED S. CAVARETTA, JR. One-sided inequalities for the successive derivatives of a function

L. CESARI and M. B. SURYANARAYANA. Existence theorems for Pareto optimization in Banach spaces 